\title{
Lower Back Pain; Evolution of Back School Therapy
}

\section{Younis Kamal}

Department of Orthopaedics, Bone and Joint Hospital, Barzullah, GMC, Srinagar, India

\begin{abstract}
Back school therapy is a kind of patient education to teach him to how to help him and take active part in the management of the back pain. This is a group therapy of education, flexibility, strength, coordination and endurance training to prevent repetitive micro-trauma to the spinal structures responsible for pain and degeneration. The purpose of back school is not only to create confidence in the patient to cope with his back troubles but also to avoid excess therapy and to decrease the expenses both for the patient and for the society. It is the endeavour of many people which gave birth to the present form of back school concept and design which has not only refined many lives but added one important dimension in the management of low back pain.
\end{abstract}

Keywords: Back school therapy, Back pain

\section{Introduction}

A Swedish Therapist Marianne Zachrisson Forssell [1] introduced the concept of Back school in 1970. The purpose of back school is not only to create confidence in the patient to cope with his back troubles but also to avoid excess therapy and to decrease the expenses both for the patient and for the society. For most of the sufferers of low back pain without overwhelming complaints, the 'Back School' approach is most useful.

Back school is a kind of patient education to teach him to how to help him and take active part in the management of the back pain. This is a group therapy of education, flexibility, strength, coordination and endurance training to prevent repetitive micro-trauma to the spinal structures responsible for pain and degeneration (Kulkarni) [2]. In the yesteryears chronic low back pain was treated with analgesics / bed rest or surgery. However, today there is much more emphasis on exercise, psychotherapy, consideration of ergonomics and less so on surgery.

The back school instructions usually begin with description of pertinent anatomy in terms understandable by even the less educated. Various audiovisual aids are used. The initial discussion leads to the information on function of spine and present knowledge of low back pain. The mechanics of spine are explained and patients are taught the postures and positions most beneficial to the back. Various exercises to strengthen the abdominal, back and gluteal muscles are taught. There are wide variations in opinion as to what exercises are the most beneficial; at present no clear cut advantage of one type over the others seems available, no matter what disease process was being treated. The back school can also include an exam to avoid misunderstandings. Physical activities, sports and games are encouraged to improve psychological and physical tolerance of pain.

The back school program can also be applied to a variety of definite conditions such as prolapsed intervertebral disc, stenosis and spondylolisthesis for their effective management and even proper postoperative care.

Thus the back school method emphasizes that back disability is often part of human condition; that everyone bears responsibility for his own health and one cannot place all the blame at the door of other individuals. Back school also removes much of mystique about the back disability. Because the patients are endowed with more responsibility for their cure they are more unlikely to fall prey to various magic cures unless their specific validity is demonstrated.

\section{Evolution of Back School Therapy}

Humans have been plagued by back pain since the beginning of recorded history. Early Greeks recognized the symptoms as a disease and prescribed rest and massages for the ailment.

Imphotep (2800 BC) is linked to authorship of "Edwin smith Papyrus" a manual on trauma to head, upper limbs and spine. Manual ends with an account of management of lumbar sprain.

Friberg [3] reported that any disturbances of the mechanical function of the lower part of back because of ligamentous, periosteal, muscular and fascial lesions may initiate somewhat similar combination of signs and symptoms and are identified by physical examination i.e. spinal tenderness and restriction of spinal movements.

Magnusson [4] said that low back can be and frequently is the site of sudden severe pain followed by sciatic pain in days, weeks, or months which may be due to combination of physiological degeneration of supporting tissues, infection, toxemia, arthritis or combination of two or more. A large number of these patients get well with rest, traction and adequate treatment of systemic condition. Disc removal without definite evidence of root pressure is not justifiable until every other method has been reasonably tried.

Friberg and Hirsch [5] examined 1500 cases of back pain and found that symptoms began in late 20s and that the highest incidence of pain was between the ages of 30 and 50 years, with equal incidence in men and women.

Burn and Young [6] noted that the low back pain and sciatica must be among the commonest disorders that affect mankind; probably they are the part of price we pay for our upright posture.

Nathan [7] observed higher incidence of lumbosacral arthritis, lumbar curvature changes in persons engaged in heavy activities like carrying and lifting heavy objects.

Hirsch [8] concluded that even though strong evidence points to the intervertebral disc as the site of pathophysiological process that acts as a trigger mechanism in low back pain, analysis of patient's symptoms disclosed a complex picture with marked variation in the distribution of pain and varied degrees of impaired function. It is clear that the pain

*Corresponding author: Younis Kamal, Kandizal Pampore, Pulwama, Srinagar Jammu and Kashmir, India, Tel: 09906966960; E-mail: kdryounis@gmail.com

Received May 13, 2015; Accepted July 22, 2015; Published July 24, 2015

Citation: Kamal Y (2015) Lower Back Pain; Evolution of Back School Therapy. J Spine 4: 238.doi:10.4172/21657939.1000238

Copyright: (c) $2015 \mathrm{Kamal}$ Y. This is an open-access article distributed under the terms of the Creative Commons Attribution License, which permits unrestricted use, distribution, and reproduction in any medium, provided the original author and source are credited. 
may originate in other elements such as ligaments, joints, fascia and muscles, all of which are involved in the mechanical behaviour of the back.

Dixon [9] concluded that 9 out of 10 instances of low back pain are transient related to some postures or strain. Recovery can take place in short time.

Bergquist -Ullman and Larsson [10] concluded that Back school therapy was as helpful as more vigorous physical therapy program and significantly better than placebo (short wave diathermy). Patients in back school therapy had significantly less time absent from work as compared to groups in physical therapy and placebo.

Fairbanks et al., [11] developed The Oswestry low back pain disability questionnaire to assess the functional disability of the patient. They interpreted the results that could be obtained from this questionnaire as follows: 0-20 minimal disability; 20-40 moderate disability; $40-60$ severe disability; $60-80$ crippled; $80-100$ bed bound.

Robinson [12] stated that the Canadian Back Education Unit represents a team approach to a medical problem. Orthopaedic surgeons, psychiatrists, psychologists and physiotherapists give a course of four lectures to patients with low back pain. The patients are taught the anatomy and physiology of their pain, proper postures and exercise, the way in which emotions can complicate their physical problem, and relaxation techniques. He reported that of 934 patients completing the six-month review course, $77 \%$ rated themselves as improved and $96 \%$ felt the course had been helpful. There was also found to be a $62 \%$ decrease in the number of patients seeing doctors about their back pain. It was felt that this is a method by which psychiatrists, orthopedic surgeons and paramedical personnel are able to work together to provide an effective and cost-efficient way of helping patients cope with a chronic physical problem.

Zachrisson Forssell [1] stated that the Back School was first organized in 1970 at Danderyd hospital, near Stockholm. It soon replaced most of the treatment modalities previously used in the physiotherapy department for patients with low back pain. Following the early successful results, the Back School spread to more than 300 back care institutions in the Scandinavian countries- hospitals, industries and schools. It was also introduced in the United States, Great Britain and Australia.

Kvein et al., [13] compared two groups of patients with low back pain. One had education program combined with practice of exercises and correct use of back where as other group had usual physiotherapeutic measures. The patients in educational program were statistically in less need of physiotherapy after leaving hospital. $\mathrm{He}$ concluded that the education program is beneficial for the patients and of economic importance for the society.

Hall et al., [14] reported that the Canadian Back Education Units (CBEU), in a review of 6418 participants, found a significant subjective improvement in $69 \%$ of the participants.

This figure improved to $80 \%$, when only patients who experienced back pain for six months or less were considered. Ninety-seven percent of the participants considered the back education program helpful. Patients who had completed their high school education, who believed that they understood the mechanism of the pain, and who recognized an emotional component to the problem had the best results. Functional improvement was most pronounced in the activities most often performed. Patients with pain persistently radiating below the knee and patients receiving workmen's compensation did not fare as well. Using a computer analysis of the variation in test scores from pre-test to the review class, a statistically valid positive correlation was established between the patient's subjective improvement and the amount of information retained. They conclude that CBEU are an efficient, effective, well received, and cost-effective therapeutic modality in the conservative treatment of chronic low back pain.

Lankhorst et al., [15] stated that given the proven efficacy of Back school in sub-acute low back pain it should be administered when it is most beneficial i.e. in early phase of low back pains.

Sikorski [16] treated 142 patients of mechanical low back pain and assessed their response by means of a postal questionnaire. Patients were offered an educational program, exercises, spinal manipulation, spinal supports and analgesic medication. $18 \%$ of the patients became completely free of pain, $59 \%$ experienced a reduction in pain levels and $51 \%$ were more active after therapy than they had been before. He concluded that the most effective form of treatment was education in back care, with $69 \%$ claiming benefit, followed closely by an exercise program( $64 \%$ benefit $)$.

Klaber Moffett et al., [17] in a double blind controlled prospective study, treated 92 patients with chronic low back pain. The patients were randomly allocated to two groups, to evaluate the effectiveness of a back school compared with an exercise only regimen, according to specified outcome variables. The data from 78 patients with 7 years mean duration of symptoms was analyzed. Three assessments were made: before treatment and 6 and 16 weeks after treatment. Changes in patients' levels of pain, functional disability and other related variables were compared in the two groups. They reported that almost all variables showed an improvement at 6 weeks. At 16 weeks, functional disability and pain levels showed a significant difference. Back school patients continued to make an improvement. They concluded that all chronic low back pain patients would benefit from a program of back care education, such as is offered by the back school. They considered back school an important adjunct to other forms of treatment, both conservative and surgical.

Keijsers et al., [18] investigated the use of an education program for patients with chronic low back pain (Back School). The effect evaluation was based on a pretest-post-testcontrol group design, including a followup after 8 weeks. The Maastricht Back School was based on the theory that pain is also maintained by emotional, cognitive and environmental factors. Information and training were given on these and physical factors. The purpose of the course was to teach patients to manage their own pain problem. The results suggested that the Back School program for patients with chronic low back pain can have a positive effect.

Linton et al., [19] studied the effectiveness of a secondary prevention program for nurses with back pain, who were deemed at risk for developing a chronic problem. A 2 X 3 repeated measures design was employed with 2 groups and 3 assessment periods. The treatment group received an intervention designed to reduce current problems, but above all to prevent re-injury and minor pains from becoming chronic medical problems, and it included a physical and behavioural therapy package. The control group was placed on a Waiting-list. Results indicated that the treatment group had significantly greater improvements than the control group for pain intensity, anxiety, sleep quality and fatigue ratings, observed pain behaviour, activities, mood, and helplessness. These differences were generally maintained at the 6 month follow-up. In addition, the treatment group broke a trend for increasing amounts of pain-related absenteeism, while the control group did not. They concluded that a secondary prevention program, aimed at altering life style factors, may represent an effective method for dealing with musculoskeletal pain problems. 
Grardel et al., [20] stated that even severe low back pain sufferers were unaware of the basic rules for the protection of spine.

Lindstrom et al., [21] studied 103 patients with nonspecific mechanical low back pain. The patients were examined by an orthopaedic surgeon and a social worker and were randomized to an activity group $(n=51)$ and a control group $(n=52)$. Patients with defined orthopaedic, medical, or psychiatric diagnoses were excluded before randomization. The purpose of the study was to compare mobility, strength and fitness after traditional care and after traditional care plus a graded activity program with a behavioural therapy approach. They concluded that traditional care plus a graded activity program were superior to only traditional care, evaluated in terms of mobility, strength and fitness. The graded activity program proved to be a successful method of restoring occupational function and facilitating return to work in sub-acute low back pain patients.

Frank [22] stated that modern management of low back pain emphasis self-care and bed rest not more than 48 hours. Return to physical fitness and other activities including employment are actively encouraged.

Waddell [23] stated that Bed rest should be avoided whenever possible and always ended as rapidly as possible. The prescription of rest and restricted activity for chronic pain is absolutely contraindicated. There is now good evidence for an active exercise approach for chronic low back pain. He emphasized that we need a new strategy of management directed equally to pain and disability, which places equal emphasis on the symptomatic relief of pain and restoration of function.

Indahl et al., [24] stated that low back pain treated as benign, self-limiting condition with information and instructions and light mobilization gives superior results as compared to treatment with conventional medical systems.

Kuukkanen et al., [25] stated that the home exercise program could be as effective as intensive training program in increasing muscle strength, as well as decreasing back pain and functional disability among low back pain patients with mild functional limitations.

Keller et al., [26] demonstrated the effectiveness of a multidisciplinary rehabilitation program for chronic low back pain which included functional restoration, pain management strategies and back school elements.

Friedrich et al., [27] demonstrated that combined exercise and motivational program reduced disability and pain levels.

Indahl et al., [25] performed a 5-year follow-up study, to examine the long-term effect of an informative approach to low back pain, on patients included in a previous study. The outcome was measured by return to work or still on sick leave. They concluded that sub-acute low back pain may be managed successfully with an approach that includes clinical examination combined with information for patients about the nature of the problem, provided in a manner designed to reduce fear and give them reason to resume light activity.

Burton et al., [28] carried out a double-blind, randomized controlled trial of a novel educational booklet compared with a traditional booklet, for patients seeking treatment in primary care for acute or recurrent low back pain. A novel patient educational booklet, The Back Book, was developed to provide evidence-based information and advice consistent with current clinical guidelines. One hundred sixty-two patients were given either the experimental booklet or a traditional booklet. The main outcomes studied were fear-avoidance beliefs about physical activity, beliefs about the inevitable consequences of back trouble, the Roland Disability Questionnaire, and visual analogue pain scales. They reported that the patients receiving the experimental booklet showed a statistically significant, greater, early improvement in beliefs which was maintained at 1 year. A greater proportion of patients with an initially high fear-avoidance beliefs score who received the experimental booklet had clinically important improvement in fear-avoidance beliefs about physical activity at 2 weeks, followed by a clinically important improvement in the Roland Disability Questionnaire score at 3 months. There was no effect on pain. They concluded that carefully selected and presented information and advice about back pain can have a positive effect on patients' beliefs and clinical outcomes.

Penttinen et al., [29] in a randomized controlled trial of back school with and without peer support concluded that among the subject suffering from non-specific back pain, social support improves the results of active rehabilitation.

Akinpelu et al., [30] carried out a preliminary study to determine the effect of a back school model (BSM) on some Nigerian industrial workers' knowledge of low back pain and back care. The subjects were 110 workers of a soap industry in Lagos, Nigeria. A pre-test, post-test quasi-experimental design was used. The BSM consisted of two 45 minute teaching sessions on structure and functions of the back, epidemiology and causes of back pain, correct postures and demonstration of exercises that may prevent/alleviate back pain. They concluded that the BSM was effective in improving the workers' knowledge of LBP and back care. They believed that this finding justified the effort to develop the Nigerian model of back school.

Keller et al., [26] concluded that patients with chronic low back pain who followed cognitive intervention and exercise programs improved significantly in muscle strength as compared to the patients who underwent lumbar fusion.

Heymans et al., [31] carried out a systematic review within the Cochrane Collaboration Back Review Group to assess the effectiveness of back schools for patients with nonspecific low back pain (LBP). They searched the MEDLINE and EMBASE databases and the Cochrane Central Register of Controlled Trials to November 2004 for relevant trials reported in English, Dutch, French, or German. They also screened references from relevant reviews and included trials. Randomized controlled trials that reported on any type of back school for nonspecific LBP were included. Four reviewers, blinded to authors, institution, and journal, independently extracted the data and assessed the quality of the trials. Nineteen randomized controlled trials (3,584 patients) were included in this updated review. They concluded that there is moderate evidence suggesting that back schools, in an occupational setting, reduce pain and improve function and return -to -work status, in the short -and intermediate -term, compared with exercises, manipulation, myofascial therapy, advice, placebo, or waiting list controls, for patients with chronic and recurrent low back pain.

Shirado et al., [32] performed a prospective cohort study with the objective of introducing a novel back school for the treatment of patients with chronic low back pain (CLBP), and to report its clinical results. A total of 182 patients with CLBP (74 men and 108 women; average age, 43.8 years) participated in this study. There was statistically significant improvement of finger-floor distance, trunk muscle strength, and endurance in the patients whose pain was relieved after enrolment in the program $(\mathrm{P}<0.05)$. The compliance with the exercise program was significantly correlated with the clinical results $(\mathrm{P}<0.05)$. They concluded that teaching body mechanics and performing the therapeutic exercises through the multidisciplinary team approach are essential to managing CLBP in a general setting. 
Karkucak et al., [33] carried out a study on 44 patients with chronic low back pain. The patients attended back school program, and were evaluated for effectiveness of this program, and their socioeconomic and low back pain features. They reported that the results of pain intensity (VAS), lumbar ROM and functional disability after the back school were found to be significantly improved ( $\mathrm{p} 0.05$ ). They concluded that female sex and low educational level are important risk factors for back pain and back school is an effective adjunctive procedure in alleviating subjective and objective symptoms of patients with chronic low back pain. They also concluded that back school be an alternative treatment procedure to other physical therapy modalities as it is a cost effective method. In summary the aims of Back School therapy are:

1. To enable the patients to play an active part in improving their working environment in order to reduce their back problem.

2. To provide increased knowledge, that gives better understanding and so reduces the risk of inappropriate therapy.

3. To reduce the demands for social, medical and economic resources that is caused by avoidable back pain.

\section{References}

1. Zachrisson Forssell M (1981) The back school. Spine 6: 104-106.

2. Kulkarni GS (1999) Conservative care of Back pain and Backschool therapy. Text Book of Orthopedics and Trauma. 1: 2770-2785

3. Joseph A, Freiberg MD (1939) Low back pain - correlation of some of the signs and symptoms. JAMA 113: 2195-2198.

4. 4. Magnusson PB (1944) Differential diagnosis of causes of pain in the lower back accompanied by sciatic pain. Am surg 119: 878-891.

5. Friberg S, Hirsch C (1946) On late results of operative treatment of intervertebral disc prolapses in the lumbar region. Acta Chir Scand 93: 161-168.

6. Burn BH, Young RH (1951) Results of surgery in sciatica and low back pain. Lancet 1: 245-249.

7. Nathan $\mathrm{H}$ (1959) Spondylosis; Its anatomy and mechanism of development. J Bone Joint Surg 41A: 303-320.

8. Hirsch C (1965) Efficiency of surgery in lowback disorders. J Bone Joint Surg 47A: 991-1004.

9. Dixon AST and Campbell-Smith S (1969) Long Leg Arthropathy. Ann Rhem 28: 359-365.

10. Bergquist- Ullman M and Larsson U (1977) Acute low back pain in industry. A controlled prospective study with special reference to therapy and confounding factors. Acta orthop scand, suppl 170: 1-117

11. Fairbank JC, Couper J, Davis JB, O'Brian JP (1980) The Oswestry low back pain disability questionnaire. Physiotherapy 66: 271-273

12. Robinson GE (1980) A combined approach to a medical problem. The Canadian back education unit. Can J Psychiatry 25: 138-142.

13. Kvien TK, Nilsen H, Vik P (1981) Education and self-care of patients with low back pain. ScandJRheumatol $10: 318-320$.

14. Hall H, Iceton JA (1983) Back school: an overview with special reference to the Canadian back education units. Clin Orthop Relat Res 179: 10-17.

15. Lankhorst GJ, Van de Stadt RJ, Vogelaar TW, Van der Korst JK, Prevo AJ (1983) The effect of the Swedish Back School in chronic idiopathic low back pain. A prospective controlled study. Scand J Rehabil Med 15: 141-145.

16. Sikorski JM (1985) A rationalized approach to physiotherapy for low-back pain Spine 10: 571-579.

17. Klaber Moffett JA, Chase SM, Portek I, Ennis JR (1986) A controlled, prospective study to evaluate the effectiveness of a back school in the relief of chronic low back pain. Spine 11: 120-122.

18. Keijsers JF, Groenman NH, Gerards FM, van Oudheusden E, Steenbakkers M (1989) A back school in The Netherlands: evaluating the results. Patient Educ Couns 14: 31-44.
19. Linton SJ, Bradley LA, Jensen I Spangfort E Sundell L (1989) The secondary prevention of low back pain: a controlled study with follow-up. Pain 36:197-207.

20. Grardel B, Sutter B, Plais PY, Samaille V, Cappelaere A, et al. (1991) The school for patients with chronic backache. Retrospective study of 93 severely handicapped patients with backache and their socio-occupational status. Rev Rhum Mal Osteoartic 58: 513-518.

21. Lindstrom I, Ohlund C, Eek C, Wallin L, Peterson LE, et al. Mobility, strength, and fitness after a graded activity program for patients with subacute low back pain. A randomized prospective clinical study with a behavioral therapy approach. Spine 17: 641-652.

22. Frank A (1993) Low back pain. BMJ 306: 901-919.

23. Waddell G (1993) Simple low back pain: rest or active exercise. Ann Rheum Dis $52: 317-319$.

24. Indahl A, Haldorsen EH, Holm S, Reikeras O, Ursin H (1998) Five-Yea Follow-Up Study of a Controlled Clinical Trial Using Light Mobilization and an Informative Approach to Low Back Pain. Spine 23: 2625-2630.

25. Kuukkanen T and Malkia E (1996) Muscular performance after a 3 month progressive physical exercise program and 9 month follow-up in subjects with low back pain. A controlled study. Scand J Med Sci Sports 6: 112-121.

26. Keller S, Ehrhardt-Schmelzer S, Herda C, Schmid S, Basler HD (1997) Multidisciplinary rehabilitation for chronic back pain in an outpatient setting: a controlled randomized trial. Eur J Pain 1: 279-292.

27. Friedrich M, Gittler G, Halberstadt Y, Cermak T, Heiller I (1998) Combined exercise and motivation program: effect on the compliance and level of disability of patients with chronic low back pain: a randomized controlled trial. Arch Phys Med Rehabil 79: 475-487.

28. Burton AK, Waddell G, Tillotson KM, Summerton N (1999) Information and advice to patients with back pain can have a positive effect. A randomized controlled trial of a novel educational booklet in primary care. Spine 24: 24842491.

29. Penttinen J, Nevala-Puranen $\mathrm{N}$, Airaksinen $\mathrm{O}$, Jaaskelainen $\mathrm{M}$, Sintonen $\mathrm{H}$ et al. (2002) Randomized controlled trial of back school with and without peer support. J Occup Rehabil 12: 21-29.

30. Akinpelu AO, Odebiyi DO (2004) Nigerian back school model: development and effect on industrial workers' knowledge of back pain and back care. Afr J Med Sci 33: 201-205

31. Heymans MW, Van Tulder MW, Esmail R, Bombardier C, Koes BW (2005) Back schools for nonspecific low back pain: A systematic review within the framework of the Cochrane Collaboration Back Review Group. Spine 30: 21532163.

32. Shirado O, Ito T, Kikumoto T, Takeda N, Minami A (2005) A novel back schoo using a multidisciplinary team approach featuring quantitative functional evaluation and therapeutic exercises for patients with chronic low back pain: the Japanese experience in the general setting. Spine 30: 1219-1225.

33. Karkucak M, Tuncer I, Guler M, Capkin E, Tosun M, et al. (2006) Demographic Features of the Patients with Chronic Low Back Pain and Effectiveness of Back School. Rheumatism 21: 87-90. 